\title{
A CIDADE, A SOCIEDADE E OS PODERES CONSTITUIDOS: UMA NOVA FORMA DE GESTÃO DEMOCRÁTICA POR MEIO DA PARTICIPAÇÃO
}

\author{
THE CITY, SOCIETY AND THE PERMITTED POWERS: A NEW FORM OF \\ DEMOCRATIC MANAGEMENT THROUGH PARTICIPATION
}

\begin{abstract}
Luigi Bertoncini ${ }^{1}$
RESUMO: Este artigo apresenta uma discussão teórica que parte das descobertas realizadas em uma pesquisa de mestrado defendida na área de Desenvolvimento Humano: Formação, Políticas e Práticas sociais, que teve como objetivo o estudo da participação do cidadão em conselhos municipais de gestão de políticas públicas. Uma nova concepção de gestão pública por meio da efetiva participação democrática, do cidadão, de entidades e organizações e dos diversos segmentos da sociedade junto as coisas públicas é que possibilita que a sociedade tenha acesso e a efetiva atuação nas decisões e na formulação, execução e acompanhamento de planos, programas e projetos de desenvolvimento urbano. De fato, é um novo olhar para esta dimensão tão desgastada nos dias atuais quando se trata, por exemplo, de audiência pública ou algo semelhante. É uma nova perspectiva de gestão sem atravessador, políticos, assim atuação direta junto ao poder executivo para definir aquilo que é difuso e coletivo, saindo da esfera do personalismo e interesse pessoal, passando sempre para o que é de interesse geral e bem comum.
\end{abstract}

Palavras - chaves: Conselho, Participação popular, Direitos, Democracia participativa.

ABSTRACT: This article presents a theoretical discussion based on the discoveries made in a master's research defended in the area of Human Development: Training, Policies and Social Practices, which aimed to study citizen participation in municipal councils for public policy management. A new conception of public management through the effective democratic participation, of the citizen, of entities and organizations and of the different segments of society in relation to public things is what allows society to have access and the effective performance in the decisions and in the formulation, execution and monitoring of urban development plans, programs and projects. In fact, it is a new look at this dimension that is so worn nowadays when it comes, for example, to a public hearing or something similar. It is a new perspective of management without an intermediary, politicians, thus acting directly with the executive power to define what is diffuse and collective, leaving the sphere of personalism and personal interest, always moving to what is of general and common interest.

Keywords: Council, Popular participation, Rights, Participatory democracy.

\footnotetext{
I Mestre em Desenvolvimento Humano: Formação, Políticas e Práticas sociais, UNITAL, PósGraduação em Formação Política dos Cristãos Leigos. Pontifícia Universidade Católica do Rio de Janeiro.- PUC - RJ. E- mail: lbcini@gmail.com.
} 


\section{INTRODUÇÃO}

O Brasil é um Estado Democrático de Direito. O poder político é do povo, assim a Constituição da República Federativa do Brasil garante às pessoas os direitos individuais e coletivos, sociais, civis e políticos.

Estes direitos estão garantidos na Lei, ou seja, no papel, mas para sua efetivação e atender a demanda nas diversas áreas da política pública foi necessário muita mobilização e articulação entre a sociedade civil e o poder público ao longo da história do Brasil.

As lutas por igualdade e liberdade ampliaram os direitos políticos (civis) e, a partir destes, criaram os direitos sociais - trabalho, moradia, saúde, transporte, educação, lazer, cultura, os direitos das chamadas "minorias" mulheres, idosos, negros, homossexuais, crianças, índios e o direito à segurança planetária, as lutas ecológicas e contra as armas nucleares (CHAUÍ, 200o).

A garantia dos direitos de cada cidadão brasileiro deve e pode ser exercida de através da participação popular nos espaços públicos, como os conselhos de gestão da política pública, das mobilizações sociais, e do conhecimento dos direitos e principalmente o exercício da cidadania.

A sociedade passou a recriar os vínculos organizatórios e representativos da população, que se manifestaram de diversas formas, como associativas, religiosas, profissionais, classistas, partidárias e corporativas, visando a defesa dos ideais ou interesses dos diversos segmentos da população.

Porém, nem sempre a sociedade está organizada e muito menos mobilizada para atuar e estabelecer a paridade nos espaços que ela deve estar ocupando, fazendo assim com que as decisões políticas continuem exclusivas do poder público e seus aliados.

Uma das formas do poder político ser exercido pelo povo é através do controle social. O conceito de controle social indica a participação da sociedade civil ou da população em geral na elaboração, acompanhamento e verificação (ou monitoramento) das ações de gestão pública. Na prática, significa definir diretrizes, realizar diagnósticos, indicar prioridades, definir programas e ações, avaliar os objetivos, processos e resultados obtidos. Assim é possível perceber a concepção de cogestão pública, através da participação (RICCI, 2006).

Com a descentralização nos níveis federal, estadual e municipal, novas atribuições foram dadas aos municípios. As prefeituras passaram a ter maiores responsabilidades nas áreas de saúde, educação básica e assistência social. Com isso, elas ganharam mais poder e mais autonomia para atuar nessas áreas. Por outro lado, ganharam mais responsabilidades e atribuições a serem cumpridas. Essa nova divisão de poderes fez com que as decisões e o 
governo ficassem mais próximos das pessoas. Essa nova distribuição de responsabilidades, atribuições de tarefas e recursos foi chamada de descentralização (TEIXEIRA, 1996).

Para Oliveira (2003) a democracia produz avanços na construção das relações sociais e políticas que apontam para o fortalecimento da sociedade e melhor definição de estado. Assim a sociedade ganha consistência e impulsiona a constituição de parâmetros políticos que norteiam novas relações entre o Estado e a sociedade na redemocratização.

A execução e o controle das políticas públicas no país apontam também para a necessidade de fortalecer a cultura de participação social dos cidadãos, como estratégia imprescindível de garantir o atendimento das demandas da população.

Desta forma o Estatuto da cidade² no Art. Io - Parágrafo único.

Para todos os efeitos, esta Lei, denominada Estatuto da Cidade, estabelece normas de ordem pública e interesse social que regulam o uso da propriedade urbana em prol do bem coletivo, da segurança $e$ do bem-estar dos cidadãos, bem como do equilíbrio ambiental.

Quer restabelecer uma forma organizada e por objetivo ordenar o pleno desenvolvimento das funções sociais da cidade e da propriedade urbana.

No art. $2^{\circ}$ do Estatuto da Cidade, inciso II - que preconiza a gestão democrática por meio da participação da população e de associações representativas dos vários segmentos da comunidade na formulação, execução e acompanhamento de planos, programas e projetos de desenvolvimento urbano, é pertinente que o município tenha uma forma inovadora, planejada e articulada, nos diversos setores da sociedade civil organizada e da população.

Para uma efetiva participação com envolvimento, conhecimento e imparcialidade política, é que apresento uma nova forma de organizar a população na CIDADE.

\section{CIDADE}

A organização de uma CIDADE cada vez se torna mais complexa na mesma proporção que ela se desenvolve, aumenta a população e consequentemente as demandas sociais, econômicas e políticas.

Na Lei 10.257/200I - "Estatuto da Cidade" no Art. 45 preconiza:

Os organismos gestores das regiões metropolitanas e aglomerações urbanas incluirão obrigatória e significativa participação da população e de associações representativas dos vários segmentos da comunidade, de modo a garantir o controle direto de suas atividades e o pleno exercício da cidadania

\footnotetext{
${ }^{2}$ LEI No ${ }^{\circ}$ 0.257, DE 1o DE JULHO DE 2001. Regulamenta os arts. I82 e i83 da Constituição Federal,
} estabelece diretrizes gerais da política urbana e dá outras providências. (Estatuto da Cidade) 
Para garantir a participação e o efetivo exercício da cidadania é necessário um esforço e organização da administração pública direta municipal para realização de ações que garantam a participação popular nas decisões de governo, como audiências públicas, orçamento popular, entre outros, porém estes tem se mostrado de pouco interesse da grande parte da sociedade e um baixa participação por diversos motivos, principalmente o baixo conhecimento das coisas públicas, como orçamento, ou pela politização partidária que se dá nestes espaços.

Diante desta situação como proceder e o que fazer para que a cidadania seja exercida e de fato a população seja atendida nas suas reais necessidade, anseios e desejos?

A experiência do controle social por meio dos conselhos municipais tem apontado como uma forma eficaz de participação, quando exercido de fato por uma lei municipal bem elaborada, pelo engajamento da sociedade civil organizada para sua participação e representação nestes espaços de participação e democracia, e pela não ingerência do poder público ou Governo nas decisões e resoluções dos conselhos.

Em uma experiência recente de implantação de uma metodologia de atuação do poder público municipal juntos aos inúmeros conselhos municipais, no município de São José dos Campos - SP, desenvolvi um programa que se intitulou Comitê de Conselhos³, cuja função é a Gestão e assessoramento dos conselhos municipais, com os objetivos: Integrar, tornar a gestão mais transparente, ética e democrática, e dar mais visibilidade às atividades dos conselhos, que teve grandes avanços e ganhos para a administração municipal como para a efetiva participação do cidadão nos conselhos municipais.

Diante desta exitosa experiência desenvolvi outro estudo com referência neste acima descrito onde amplia o alcance e inova na forma da participação.

Este artigo tem a intenção de mostrar como é possível com pouquíssimos recursos articular parte importante e substancial da sociedade para estar junto nas decisões e planejamento urbano do município. Ser um canal de interlocução direta da sociedade junto ao órgão público na efetivação das políticas públicas, serviços, obras, campanhas, enfim tudo aquilo que é do trato público e de interesse coletivo e de melhoria de condições para a população e desenvolvimento da cidade.

\section{METODOLOGIA}

Para desenvolver uma forma de se realizar ações e eventos de participação efetiva da população na organização da CIDADE, apresento o Conselho da Cidade, que é formado por representações de setores importantes e fundamentais do município, como conselhos

\footnotetext{
3 https://www.sjc.sp.gov.br/servicos/governanca/portal-da-transparencia/conselhos/comite Sitio oficial da Prefeitura Municipal de São José dos Campos
} 
municipais e conselhos distritais. Por isso a importância do comitê de conselhos para que se tenha diversos conselhos municipais ativos e participativos. A novidade que apresento e necessário é a criação de conselhos distritais de acordo com a regionalização demográfica e territorial, analisando os contextos sociais e econômicos.

O Conselho Distrital é um conselho, consultivo e informativo, de uma determinada região do município composto de vários bairros, com representações dos diversos atores da sociedade local. Com objetivo de ser um canal de interlocução entre sociedade e poder público para tratar de assuntos referentes ao interesse geral e coletivo do distrito e do município, garantindo a participação da população, e seus objetivos específicos:

I. Articular a população em geral a respeito de ações do poder público, nas 3 esferas, fazendo com que as informações, campanhas, audiências públicas e ações atinjam o maior número de pessoas;

2. Ser um canal de solicitações, requerimentos das necessidades do distrito.

3. Permitir aos cidadãos influenciar ou decidir sobre os orçamentos públicos, com assembleias abertas e periódicas e etapas de negociação direta com o governo.

4. Garantir a participação popular na definição de políticas governamentais para o distrito.

O Conselho Distrital é organizado de forma horizontal na sua composição, sendo constituído por representantes dos diversos setores da sociedade, como comercio, serviços, equipamentos públicos, associações, entidades e Igrejas. Cada Conselho Distrital tem autonomia e prerrogativas sobre seu território definido, bem como a interação com os setores do poder público. Toda a definição será especificada em lei municipal própria que deverá prever o número de componentes, quais setores, periodicidade de reuniões e outras atribuições.

O que é então o CONSELHO DA CIDADE?

Este será constituído por representantes dos conselhos municipais legalmente instituídos e funcionando ativamente, além de um representante de cada conselho distrital e representante do Poder público municipal ligado ás áreas pertinentes de planejamento, formando assim um grande conselho que irá planejar, organizar e orientar o município juntamente com as prerrogativas legais do Estado, em seu plano diretor, leis e orçamento.

O Conselho da Cidade é um modo por excelência onde será assegurando o atendimento das necessidades dos cidadãos quanto à qualidade de vida, à justiça social e ao desenvolvimento das atividades econômicas, para garantir a gestão democrática da cidade, e deverão ser utilizados, entre outros, os seguintes instrumentos:

I - Órgãos colegiados de política urbana, nos níveis nacional, estadual e municipal; 
II - Debates, audiências e consultas públicas;

III - conferências sobre assuntos de interesse urbano, nos níveis nacional, estadual e municipal;

IV - Iniciativa popular de projeto de lei e de planos, programas e projetos de desenvolvimento urbano;

O Conselho da Cidade promoverá em conjunto com poder público a realização de debates, audiências e consultas públicas sobre as propostas do plano plurianual, da lei de diretrizes orçamentárias e do orçamento anual, como condição obrigatória para sua aprovação pela Câmara Municipal.

\section{CONSIDERAÇÕES FINAIS}

A implantação destes organismos democráticos em cada município trará maior transparência e participação efetiva da população e do comprometimento do cidadão com sua CIDADE. Assim tanto o poder público (ESTADO) como a sociedade civil terão um canal de Comunicação que permite troca rápida de informação, ações e campanhas públicas, trazendo cada vez mais uma resposta rápida, com otimização de recursos públicos, uma vez que a informação circulará no meio da sociedade por meio de seus representantes juntos as organizações a que estão vinculados e sua rede de contatos. E por outro lado o poder público estará sendo sempre municiado de sugestões, solicitações e pedidos de interesse coletivo para melhoria do município.

Outro ganho nesta forma de organizar a CIDADE, é o conhecimento técnico e aprendizagem de cidadão comum em relação a forma de gerir o município e de sua participação seja, nos conselhos municipais, na organização de seu bairro ou nos conselhos distritais, de forma que muitas pessoas são envolvidas em toda etapa de planejamento e organização, e com o tempo muito mais pessoas estarão envolvidas, com conhecimento e experiências, sendo assim multiplicadores e a sociedade cresce no saber e fazer.

É necessário acreditar e dar oportunidade para que as pessoas possam exercer seu direito de cidadania na participação democrática na organização de sua cidade, proporcionando que ela seja protagonista e não simplesmente alguém que fica esperando que um representante o faça por ela. O cidadão se torna parte do todo e não mero expectador.

Para além da democracia representativa queremos uma democracia participativa e cada um exercendo sua atribuição, tendo uma função e sentido dentro do sistema político vigente. É preciso romper com a morosidade, comodismo e superar os desmandos políticos dentro da coisa pública, queremos ser protagonistas da própria história e ter a hombridade e orgulho de 
poder contribuir e fazer parte da história e o melhor, das melhorias da condição da minha rua, do meu bairro, da minha região e enfim da minha CIDADE.

Poder fazer diferente é um dever e uma obrigação, principalmente para que muito sejam beneficiados e sejam tratados com dignidade.

\section{REFERÊNCIAS}

BRASIL. Constituição (1988). Constituição da República Federativa do Brasil: promulgada em 5 de outubro de 1988. Senado Federal, Gráfica do Senado, Brasília/DF, 1989.

BRASIL LEI No 10.257, DE ro DE JULHO DE 2001. Estatuto da Cidade, regulamenta os arts. I82 e I83 da Constituição Federal, estabelece diretrizes gerais da política urbana e dá outras providências. Brasília/DF, 200I.

CHAUÍ, M. Convite à Filosofia. Ed. Ática, São Paulo, zooo.

M. Considerações sobre a democracia e os obstáculos à sua concretização. In: TEIXEIRA, A. C. C., (Org.). Os sentidos da democracia e da participação: Instituto Pólis, São Paulo 2005. p. 23-30.

BERTONCINI, L. Análise dos Controladores Sociais: a concepção dos conselheiros sobre sua participação nos conselhos de gestão das Políticas Públicas. Dissertação (mestrado) Programa Desenvolvimento Humano. Universidade de Taubaté, Taubaté/SP, 2010.

OLIVEIRA, F M. Cidadania e cultura política no poder local. Fundação Konrad Adenauer, Fortaleza, CE 2003.

RICCI, R. (org). Participação Popular: dicionário do gestor público. Instituto Cultiva, Maringá SC, 2006.

TEIXEIRA, E C: Movimentos Sociais e Conselhos. Cadernos ABONG, nำ 15, Julho de 1996. 